\title{
Prophylaxis of Pulmonary Embolism
}

\author{
N. L. BROWSE, ${ }^{*}$ M.D., F.R.C.S.
}

The prevention of pulmonary embolism presents two problems. Total prevention-by stopping the development of thrombi in the deep veins of the lower limbs-is the first, more important and inevitably the more difficult and secondly is the prevention of embolism after the deep vein thrombi have formed, a problem which will disappear when we have an effective method of total prophylaxis.

All prophylaxis depends on an exact knowledge of the aetiology of the disease we are trying to prevent. As we do not know for certain what causes deep vein thrombosis most of our methods of prevention are empirical and ineffective. Before discussing these methods it is necessary to consider current views on the aetiology of deep vein thrombosis.

\section{Aetiology of Deep Vein Thrombosis}

The three factors which catalyse thrombus formation and intravascular coagulation are changes in the rate of blood flow, changes in the vessel wall, and changes in the nature of the blood. These factors, which were enumerated over a hundred years ago by Rudolph Virchow, ${ }^{47}$ are still our main guide lines.

The various causes of changes in blood flow are well known. The antithrombotic properties of the vein wall may be altered by local trauma, and intimal damage is positively thrombogenic. The changes in the blood include changes of viscosity, fibrinogen level, antifibrinolysis, platelet stickiness, and the concentration of the coagulation factors.

All current forms of prophylaxis attempt to change one or other of these three supposedly important predisposing conditions.

\section{Aetiology of Pulmonary Embolism}

As soon as a thrombus has formed in the deep veins there is a risk of pulmonary embolism, but we do not know why thrombi fragment. Two mechanisms could be involved. Firstly, mechanical forces-such as direct trauma, muscle action, or sudden changes in the rate of blood flow-could have a role. The second possible mechanism and probably the more important, is spontaneous fragmentation caused by the natural mechanisms of thrombolysis. Both these factors will be difficult to influence. However, once a thrombus has formed it can be prevented from reaching the lungs by removing it, dissolving it or locking it in the legs.

\section{Prevention of Deep Vein Thrombosis}

\section{Anticoagulants}

A thrombus begins as a small plaque of platelets covered by a mesh of platelets and fibrin, but the part that becomes a serious embolus is the soft, red propagating tail that grows on the initial white head. The final common path that produces this dangerous propagating tail is intravascular coagulation, consequently the most effective method of prophylaxis available is the administration of anticoagulants. Several workers $^{48-50}$ have shown that the incidence of fatal pulmonary embolism is reduced when patients are given anticoagulants

* Hon. Consultant Surgeon, Reader in Surgery, Surgical Unit, St. Thomas's Hospital, London S.E.1. immediately after major surgery, the best of these studies being based on post mortem evidence. ${ }^{51}$ However, it should not be assumed that because anticoagulants reduce the incidence of pulmonary embolism they abolish deep vein thrombosis. There is no reason why the initial platelet thrombus should not form, as anticoagulants do not alter platelet aggregation. This statement is supported by recent work, ${ }^{52} 53$ which has shown that anticoagulants given immediately after surgery do not reduce the incidence of leg vein thrombosis. The only way of reconciling these two findingsnamely that anticoagulants reduce the incidence of fatal pulmonary embolism but not the incidence of leg-vein thrombi detectable by ${ }^{125}$ I-fibrinogen-is that the anticoagulants stop only the growth of the soft, red thrombus that produces the emboli.

Anticoagulants should not be given indiscriminately because they have an appreciable number of complications. Bleeding-into fresh wounds, the retroperitoneal areas, the renal tract, and sometimes the brain-is not uncommon. Most surgeons and physicians do not give prophylactic anticoagulants to all patients but reserve them for the highrisk group-the elderly, those with carcinoma, heart disease, fractured femurs, and any who have had a previous episode of venous thrombosis or pulmonary embolism.

The administration and control of anticoagulants was discussed in the section on the medical treatment of deep vein thrombosis in the B.M.F. "Clinical Progress" symposium on thromboembolism. ${ }^{51}$

\section{Antiplatelet Substances}

As the first part of a thrombus is a collection of platelets adhering to the vein wall, it should be possible to prevent thrombosis by stopping the platelets sticking together. Several substances have been shown to affect platelet aggregation, and two have been used in clinical trials.

Dipyridamole is a mild vasodilator which has been shown to reduce platelet aggregation induced by adenosine diphosphate. ${ }^{55}$ One clinical trial has been carried out ${ }^{56}$ to test its value as a prophylactic against deep vein thrombosis. Unfortunately this trial did not use an objective method of assessment, such as the ${ }^{125}$ I-fibrinogen uptake test, and so it is open to serious criticism. Nevertheless, as many patients were studied probably the proportion of patients who developed physical signs was the same in both the control and placebo groups. This trial found no evidence that dipyridamole reduced the incidence of deep vein thrombosis, but other drugs are being developed and one may yet be successful.

Dextran 70 is another substance, produced for other purposes, which has been shown to reduce platelet adhesiveness ${ }^{57}$ - particularly the adhesiveness of platelets to a damaged area of endothelium. ${ }^{58}$ It also reduces blood viscosity. Several clinical studies ${ }^{59}$-and some trials based on phlebography ${ }^{60}{ }^{61}$-have claimed that the routine administration of Dextran 70 on the day of operation and for one or two days afterwards reduces the incidence of deep vein thrombosis. A recent study, ${ }^{53}$ using the fibrinogen uptake test for diagnosis, suggests that Dextran 70 is more effective than warfarin. Further studies need to be performed as the preliminary results of several studies in different centres currently in progress, are producing conflicting results. Dextran 70 is a drug which is not without risk; it can cause bleeding during and after operation, as troublesome as anticoagulants. 


\section{Fibrinolytic Agents}

An acute fibrinolytic state can be produced by the administration of streptokinase or urokinase. Fibrinolytic activity of this degree cannot be used for prophylaxis because it abolishes the normal mechanisms of haemostasis. However, a number of workers are searching for a method of producing a prolonged mild degree of fibrinolysis. ${ }^{62}$ At present the drugs that are effective-for example, ethyloestranol and phenformin-have to be taken for a month before the dilute bloodclot lysis time is reduced by $60 \%$, so none is yet suitable for clinical use.

\section{Antistasis}

This is the field in which surgeons have made their greatest endeavour. Believing stasis to be an important factor in the development of deep vein thrombosis, surgeons have tried every conceivable method of increasing the rate of venous blood-flow after operation-for example, early ambulation, ${ }^{6:}$ raising the foot of the bed, ${ }^{6465}$ compression bandaging, ${ }^{66}$ elastic stockings, ${ }^{6768}$ and various forms of exercise machines. ${ }^{69}$ All have failed because most deep vein thrombi begin during the operation, and any form of prophylaxis which begins twenty-four hours later is too late. Realizing that the velocity of venous blood flow is lowest during an operation, ${ }^{70}$ F. S. A. Doran suggested stimulating calf muscle contractions with an electric current. ${ }^{71}$ In two clinical studies ${ }^{65} 71$ he produced evidence which suggests that the incidence of deep vein thrombosis is reduced. A trial using the ${ }^{125} \mathrm{I}-$ fibrinogen uptake test for objective assessment, ${ }^{72}$ the full details of which are soon to be published, supports his work. Stimulating the calf muscles during operation reduces the incidence of ${ }^{125}$ I-fibrinogen-detectable calf vein thrombosis by over half-a valuable and worthwhile reduction. The disadvantages of the method are that two electrodes have to be fixed on each of the calves, and connected to an electronic stimulator. This presents the well-known problems and hazards common to all electrical equipment used in the operating theatre. However, it is the first simple non-pharmacological method of proved value, and may prove to be still more useful when combined with other forms of pharmacological prophylaxis, such as antiplatelet stickiness drugs.

\section{Prevention of Damage to Vein Wall}

Surgeons should try to avoid local trauma to major veins during operation, though this is not an important cause of deep vein thrombosis, and intravenous injections should never be given into the leg veins. The minor intimal damage that can occur while the legs are resting, flaccid on the operating table, or awkwardly in bed is more difficult to avoid. Raising the heels on a pad to take the pressure off the calves is a routine procedure in all operating theatres but it will be very difficult to prove that such precautions do any good. However, these simple nursing procedures may help and should continue to be practised.

\section{Early Detection}

Total prevention of pulmonary embolism will follow when we abolish deep vein thrombosis. Though we may succeed in reducing the incidence of deep vein thrombosis after operation, by the various methods already outlined, none of them is particularly suitable for the medical or the obstetric patient, and in most published series the patient most likely to have a pulmonary embolism is the ill patient in a medical ward. Some form of acceptable prophylaxis is desperately needed for this group. Until then we must rely on early detection of the thrombosis so that it can be prevented from leaving the legs.

\section{Methods}

The embolus that kills comes from the ilio-femoral segment $^{73}$ and before it breaks free it usually fills most of the vein and obstructs the blood flow. If this happens the obstruction can be detected by a simple method such as the ultrasound flow-detector. ${ }^{775}$ It is not unreasonable to suggest that all patients in hospital should have their major veins scanned daily with the flow-detector so that symptomless iliofemoral thrombi can be detected and dealt with. This approach is based on the assumption that the large thrombus grows slowly and is present for a day or so before it breaks off. This assumption may not be correct and if these big friable thrombi grow and break off in a period of hours, or even minutes, early detection will be impossible.

An alternative, more exact, but less practical method of early detection is the ${ }^{125}$ I-fibrinogen uptake test. ${ }^{767}$ This involves giving each patient an intravenous injection of fibrinogen, daily doses of oral iodine, and scanning the legs daily with the scintillation counter. This is not a practical proposition for all patients but it is extremely valuable for the high risk patients. Furthermore, daily examinations enable the surgeon to monitor the course of the thrombosis, and so help him to decide whether to initiate treatment.

The symptomless deep vein thrombi revealed by these two methods of detection present many problems of management. Most of the small thrombi in the calf veins resolve spontaneously and do not need any treatment, but if they show signs of enlarging the patient should be given anticoagulant therapy. The large ilio-femoral thrombus is a threat to life and should be treated by surgical thrombectomy ${ }^{78}$ or thrombolysis. ${ }^{79}$ If removal is not possible emboli can still be prevented by ligating the vein on the downstream side of the most proximal part of the thrombus. Thrombectomy, thrombolysis, or vein ligation must be followed by some form of treatment which will stop new thrombus forming-that is, anticoagulants.

\section{Prevention of Recurrent Embolism}

Many patients present with a pulmonary embolus. One embolus should always be interpreted as a warning of the next, possible fatal, embolus. I believe that all such patients should have urgent bilateral phlebograms to determine the extent and nature of any residual thrombus. In a recent study $^{80}$ we showed that $40 \%$ of patients who have had a pulmonary embolism have fresh non-adherent residual thrombus and that the incidence of second emboli can be significantly reduced by active surgical treatment. In most patien's the residual thrombus is in the calf veins and a superficial femoral vein ligation is all that is required. This is a simple operation, which can be done under local anaesthesia if necessary, and has no serious morbidity. If the veins above the superficial femoral vein need to be interrupted they can be plicated rather than ligated.

It has been suggested that residual thrombus below the ilio-femoral segment is unimportant, but this is not true. Pulmonary emboli are always multiple, spatially and temporally. An ill medical patient with a poor cardiac output and an inadequate myocardium who has had four or five branches of his pulmonary artery blocked may die if he has a further small embolus. Every effort must be made to prevent anv recurrence. We have reduced recurrent embolism from $40 \%$ to $12 "$ ". by the addition of phlebography and, if required, surgery to the administration of anticoagulants.

Most surgical patients get their deep vein thrombosis and pulmonary emboli as a result of the surgical trauma-and their thrombogenic state, whatever it is, will subside in two or three weeks. Other patients with more generalized disease may be at risk for many months and the patients with 
idiopathic deep vein thrombosis and pulmonary embolism may be at risk for the rest of their life. These patients must be given anticoagulants for a long time. It is my practice to anticoagulate all patients for six months after their first embolus, and those who have had unexplained recurrent emboli before treatment was begun should be anticoagulated for many years. We will have a logical approach to the duration of anticoagulation when we know more about the aetiology of the thrombosis. Until that time an arbitrary period must be chosen. Six months is a reasonable period because this is the time that the peripheral veins take to return to normal.

This paper shows that there is a glimmer of light on the horizon and that some effective methods of prophylaxis are appearing. At present these methods are suitable only for special groups of patients, but early detection with the modern advanced methods of diagnosis, followed by vigorous treatment when indicated, can be applied to all.
1 Goodwin, J. F., The Clinical Diagnosis of Pulmonary Embolic Disease, ed. A. A. Sasahara and M. Stein, 1967. New York, Grune and Stratton.

2 Oakley, C. M., and Goodwin, J. F., Progress in Cardiovascular Diseases, 1967, 9, 495.

3 Fleming, H. A., and Bailey, S. M., British Medical fournal, 1, 1322.

- Jones, R. H., and Sabiston, D. C., jun., Monographs in the Surgical Sciences, 1966, 3, 35.

5 Robin, E. D., Julian, D. G., Travis, D. M., and Crump, C. H., New England fournal of Medicine, 1959, 260, 586

o Stevens, A. E., Lancet, 1961, 2, 1005.

7 Medd, W. E., and McBrien, D. J., Lancet, 1962, 1, 944.

8 Sabiston, D. C., jun., and Wagner, H. N., jun., fournal of Thoracic and Cardiovascular Surgery, 1965, 50, 339.

9 Kakkar, V. V., and Flanc, C., British fournal of Surgery, 1968, 55, 384.

10 Evans, D. S., and Cockett, F. B., British Medical fournal, 1969, 2, 802 .

11 Williams, J. R., Wilcox, W. C., Andrews, G. J., and Burns, R. R., Fournal of the American Medical Association, 1963, 184, 473.

12 Fred, H. L., Axelrad, M. A., Lewis, J. M., and Alexander, J. K., Fournal of the American Medical Association, 1966, 196, 1137.

13 Gorham, L. W., Archives of Internal Medicine, 1961, 108, 8.

14 Pisko-Dubienski, Z. A., British fournal of Surgery, 1968, 55, 138.

15 Del Guercio, L. R. M., Cohn, J. D., Feins, N. R., Coomaraswamy, R. P., and Mantle, L., fournal of the American Medical Association, 1966, 196, 751.

16 Diacoff, G. R., Rams, J. J., and Moulder, P. V., Surgical Clinics of North America, 1966, 46, 27.

17 Walsh, P. N., Stengle, J. M., and Sherry, S., Circulation, 1969, 39, 153.

18 Barritt, D. W., and Jordan, S. C., Lancet, 1960, 1, 1309.

19 Zilliacus, H., Acta Medica Scandinavica, 1946, Suppl. No. 171.

20 Wessler, S., and Morris, L. E., Circulation, 1955, 12, 553.

21 Crane, C., et al., Surgery, Gynecology and Obstetrics, 1969, 128, 27.

22 Gurewich, V., Sasahara, A. A., and Stein, M., Pulmonary Embolic Disease, ed. A. A. Sasahara and M. Stein, p. 162. New York, Grune and Stratton, 1965.

23 Thomas, D. P., Tanabe, G., Khan, M., and Stein, M., Pulmonary Embolic Disease, ed. A. A. Sasahara and M. Stein, p. 59. New York, Grune and Stratton, 1965.

2t Bauer, G., American fournal of Cardiology, 1964, 14, 29.

25 Murray, G., Surgery, Gynecology and Obstetrics, 1947, 84, 665.

26 Dalen, J. E., and Dexter, L., fournal of the American Medical Association, 1969, 207, 1505.

27 Browse, N. L., and James, D. C. O., Lancet, 1964, 2,.1039. 28 Hirsh, J., Hale, G. S., McDonald, I. G., McCarthy, R. A., and Pitt,
A., British Medical fournal, 1968, 4, 729.

29 Miller, G. A. H., Gibson, R. V., Honey, M., and Sutton, G. C., British Medical fournal, 1969, 1, 812.

30 Emanuel, D. A., Sautter, R. D., and Wenzel, F. J., fournal of the American Medical Association, 1966, 197, 924.

12 Fred, H. L., Axelrad, M. A., Lewis, J. M., and Alexander, J. K., Fournal of the American Medical Association, 1966, 196, 1137.

31 Tow, D. E., and Wagner, H. N., jun., New England fournal of Medicine, 1967, 276, 1053. 32 Dalen, J. E., et al., New England fournal of Medicine, 1969,

33 Chait, A., Summers, D., Krasnow, N., and Wechsler, B. M., American fournal of Roentgenology, 1967, 100, 364.

34 Miller, G. A. H., Unpublished Observations.

35 Browse, N. L., Thomas, M. L., and Pim, H. P., British Medical Fournal, 1968, 3, 717.

${ }^{36}$ Dickie, K., De Groot, W., Cooley, R., Guest, M. M., and Bond, T., Texas Reports on Biology and Medicine, 1967, 25, 613.

37 Sautter, R. D., Emanuel, D. A., Fletcher, F. W., Wenzel, F. J., and Matson, J. I., Fournal of the American Medical Association, 1967 202, 215 .

38 Tow, D. E., Wagner, H. N., jun., and Holmes, R. A., New England fournal of Medicine, 1967, 277, 1161.

39 Genton, E., and Wolf, P. S., American Heart Fournal, 1968, 76, 628.
10 Phear, D., Lancet, 1960, 2, 832.

41 Trendelenburg, F., Archiv für klinische Chirurgie, 1908, 86, 686.

42 Kirschner, M., Langenbeck: Archiv für klinische Chirurgie, vereinigt mit Deutsche Zeitschrift für Chirurgie, 1924, 133, 312

43 Sharp, E. H., Annals of Surgery, 1962, 156, 1.

44 Vossschulte, K., Stiller, H., Eisenreich, E., Zentralblatt für Chirurgie, 1964, 89, 1661

45 Encke, A., et al., Chirurg., 1966, 37, 4

46 Cooley, D. A., and Beall, A. C., jnr., fournal of Cardiovascular Sur gery, 1962, 2, 428.

47 Virchow, R. L. K., Thrombose und Embolie, in his Gesammelte Abhandlurgen zur wissenschaftlichen Medicin, p. 219, Frankfurt, Meidinger, 1856.

18 Sevitt, S., and Gallagher, N. G., Lancet, 1959, 2, 981.

19 Neu, L. T., jun., Waterfield, J. R., and Ash, C. J., Annals of Internal Medicine, 1965, 62, 463.

so Salzman, E. W., Harris, H., and DeSanctis, R. S., New England fournal of Medicine, 1966, 275, 122.

51 Sevitt, S., and Innes, D., Lancet, 1964, 1, 124.

52 Pinto, D. J., Britich fournal of Surgery, 1967, 57, 349.

53 Lambie, J. M., Barber, D. C., Dhali, D. P., and Matheson, N. A., British Medical foumal, 1970, 2, 144.

54 Flute, P. T., British Medical fournal, 1969, 4, 678.

55 Emmons, P. R., Harrison, M. J. G., Honour, A. J., and Mitchell, J. R. A., Lancet, 1965, 2, 603.

56 Browse, N. L., and Hall, J. H., Lancet, 1969, 2, 718.

57 Dhall, D. P., Bennett, P. N., and Matheson, N. A., Acta Chirurgica Scandinavica, 1968 , Suppl. No. 387, p. 75 .

58 Afors, K.-E., Hint, H. C., Dhall, D. P., and Matheson, N. A., British Medical fournal, 1968, 4, 430.

59 London, D., and Crosfill, M. L., British fournal of Clinical Practice, $1969,23,158$.

60 Ahlberg, Å., Nylander, G., Robertson, B., Cronberg, S., and Nilson, I. M., Acta Chirurgica Scandinavica, 1968, Suppl. No. 387, p. 83.

61 Johnson, S. R., Bygdeman, S., and Eliasson, R., Acta Chirurgica Scandinavica, 1968 , Suppl. No. 387 , p. 80

62 Fearnley, G. R., Chakrabarti, R., and Hocking, E. D., Lancet, 1967, 2, 1008.

63 Powers, J. H., Fournal of the American Medical Association, 1944, $125,1079$.

64 McLachlin, A. D., Stavraky, W. K., and Sweeney, J. P., Canadian fournal of Surgery, 1967, 10, 414.

65 Doran, F. S. A., White, M., and Drury, M., British fournal of Surgery, 1970, 57, 20

66 Wilkins, R. W., Mixter, G., jun., Stanton, J. R., and Litter, J., New England fournal of Medicine, 1952, 246, 360.

67 Makin, G. S., British fournal of Surgery, 1969, 56, 373.

68 Rosengarten, D. S., Laird, J., Jeyasingh, K., and Martin, P., British fournal of Surgery, 1970, 57, 296.

69 Gibbs, N. M., British fournal of Surgery, 1959, 47, 282.

70 Doran, F. S. A., Drury, M., and Sivyer, A., British fournal of Surgery, 1964, 51, 486.

7 Doran, F. S. A., and White, H. M., British fournal of Surgery, 1967, 54, 686 .

72 Negus, D., and Browse, N. L., European Surgical Research, 1970, 2, 134.

73 Mavor, G. E., and Galloway, J. M. D., Lancet, 1967, 1, 871.

74 Sigel, B., et al., Surgery, 1968, 64, 332.

75 Evans, D. S., and Cockett, F. B., British Medical fournal, 1969, 2, 802 .

76 Flanc, C., Kakkar, V. V., and Clarke, M. B., British fournal of Surgery, $1968,55,742$.

77 Negus, D., Pinto, D. J., Le Quesne, L. P., Brown, N., and Chapman, M., British fournal of Surgery, 1968, 55, 835.

78 Mavor, G. E., and Galloway, J. M. D., British fournal of Surgery, $1969,56,45$.

79 Browse, N. L., Thomas, M. L., and Pim, H. P., British Medical fournal, 1968, 3, 717.

80 Browse, N. L., Thomas, M. L., Solan, M. J., and Young, A. E., British Medical fournal, 1969, 3, 382. 